98-225 Widdowson, Henry G. (U. of London, Inst. of Ed.). The pedagogic relevance of language awareness. Fremdsprachen Lehren und Lernen (Tübingen, Germany), 26 (1997), 33-43.

This paper considers the currently fashionable notion of language awareness: what it is, where it comes from, and how far it is pedagogically valid. Awareness (of language as grammatical code) was central to language learning in grammar-translation methodology, but was played down in both structural and communicative language teaching. A communicative approach implied, however, a need to become aware of aspects of language in contextual use, though it was not always clear what the facts were of which one needed to be aware. Now that aspects of language use and of usage have been described, it is valuable that language teachers be aware of these developments. However, whether and in what sense such awareness is of pedagogical relevance cannot be determined by linguistic discovery procedures, or by investigating native-speaker norms. Classroom learning has its own agenda, and the author affirms the need above all to be aware of this.

\section{Language learning}

\section{8-226 Bardovi-Harlig, Kathleen (Indiana U.).}

Another piece of the puzzle: the emergence of the present perfect. Language Learning (Cambridge, MA), 47, 3 (1997), 375-422.

This article examines the emergence of the present perfect in the interlanguage of 16 instructed adult learners of English as a second language. It is part of a longitudinal study of the expression of temporality in interlanguage; it focuses on the learners' form-meaning associations by investigating their use of the present perfect in written and oral texts. The article first describes the order of emergence of the present perfect with respect to other tense/aspect forms and then the potential influence of instruction by comparing production to instructional logs. Examination of the linguistic contexts in which the present perfect appears shows that adding a new inflection in the tense/aspect system requires not only establishing new form-meaning associations but also revising existing ones.

\section{8-227 Bartning, Inge (U. of Stockholm)} L'apprenant dit avancé et son acquisition d'une langue étrangère: tour d'horizon et esquisse d'une caractérisation de la varieté avancée. [The so-called 'advanced' learner and his/her acquisition of a foreign language: overview of the issues and preliminary description of the 'advanced' variety.] Aile (Paris), 9 (1997), 9-50.

Based on a broad international corpus of evidence, drawn predominantly from learners of French and English, this article attempts to identify the features of language use which distinguish the 'advanced' learner from, respectively, the beginner, the 'intermediate' learner and the near-native speaker. (It is stressed that these terms as applied to individual learners do not necessarily correlate precisely with formal levels of instruction.) Evidence is presented for a continuum of ability in the target language, encompassing increasing morphological and syntactical complexity and stability, alongside developing discursive and dialogic skills and a growing sensitivity to sociolinguistic variation which approximate increasingly to those of native speakers. Particular mention is made of evidence emerging from the Swedishbased InterFra project, documenting the developing use of French by a group of Swedish university students.

\section{8-228 Bergström, Anna (Delaware U.).}

L'influence des distinctions aspectuelles sur l'acquisition des temps en français langue étrangère. [The influence of aspectual distinctions on the acquisition of tense in French as a foreign language.] Aile (Paris), 9 (1997), 51-82.

This article presents the results of a cross-sectional study of the acquisition of tense and aspect by 75 Englishspeaking classroom learners of French. The goal of the study was to test the Defective Tense Hypothesis proposed for second language acquisition by Andersen (1991). This hypothesis holds that learners initially use verb morphology to mark inherent lexical aspect of verbs, not tense or grammatical aspect. The results of the study reported here indicate that the learners make a stative/dynamic distinction. The author offers an explanation for the robust use of the passé composé with dynamic verbs and the slow emergence of the imperfect, based on an analysis of the aspectual features involved.

98-229 Borrell, A. (U. Toulouse-Le Mirail). Systématisation des erreurs de production et donc de perception chez les apprenants étrangers? [Are foreign language learners' errors in production-and hence perception-systematic?] Revue de Phonétique Appliquée (Paris), 118-119 (1996), $1-15$.

It has long been argued that a learner's speech perception and production of a foreign language are consistently and systematically based on the 'phonological filter' formed by the phonemic units and categories of the mother tongue (L1). This article reports on a research project in contrastive phonology which aimed to establish the limits of such systematicity. Specific aspects of the pronunciation of twenty learners of French as a foreign language, speaking eight different mother-tongues, were compared. Although the systematic operation of L1 'phonological filters' was largely confirmed, there was also a significant amount of interand intra-individual variation. It is suggested that this may be due to the influence of extrinsic factors including orthography, teaching methodology, and whether French was being learnt as a foreign or second language. It is also important to remember that phonological systems may vary along parameters such as region, sex or 
age within the same speech community, and that speakers of the same mother tongue may therefore possess different 'filters'.

98-230 Boyle, Joseph (Chinese U. of Hong Kong). Success and failure in learning Cantonese. Language Learning Journal (Rugby), 16 (1997), 82-6.

Cantonese is a notoriously difficult language to learn. Based on interviews with sixty learners of the language in Hong Kong, this article examines in some detail the individual cases of six successful and six unsuccessful learners, and tries to elicit the common factors which influenced their success or failure. In addition to factors which have been identified in other studies as contributing to success or failure in language learning, the author points to specific features of Cantonese and the Hong Kong context as hindrances to successful learning.

\section{8-231 Carroll, Mary and v. Stutterheim,}

\section{Christiane (U. of Heidelberg). Relations entre} grammaticalisation et conceptualisation et implications sur l'acquisition d'une langue étrangère. [The relationship between grammaticalisation and conceptualisation, and implications for second language acquisition.] Aile (Paris), 9 (1997), 83-115.

This article examines the organisation of information in learners' texts, which draws on different aspects of their linguistic knowledge. Data were gathered from advanced English-speaking learners of German confronted with complex verbal tasks such as narratives, descriptions and instructions. A fundamental problem for the understanding of the second language (L2) learning process is addressed, namely, why adult learners do not generally achieve native competence in spite of $a$ priori 'sufficient' exposure to the L2. It is suggested that learners cannot achieve native competence unless they acquire the principles organising information flow in L2 discourse, in addition to mastering the L2 grammatical structures which encode it.

\section{8-232 Devitt, Seán (Trinity Coll., Dublin).} Reading and writing one's way into language awareness. Language Awareness (Clevedon), 6, 2/3 (1997), 119-35.

This paper examines the subprocesses of reading, as they have been identified in first (L1) and second language (L2) reading research, and the two types of input that they require: the data from the text, on the one hand, and the data that the learner has stored, on the other. It argues that, through activities designed to work with each one of the subprocesses in turn, attention can be focused both on the subprocess itself and on the language data used by it, and that language awareness is thereby developed. A set of activities, designed in such a way as to match each of the subprocesses of reading, is linked to a sample text in English. It is argued that when readers carry out these activities, whether the text is L1 or L2 for them, an awareness both of the language data and of the different subprocesses of reading ensues. When the text is in L2, and stored language data are inadequate for a particular subprocess to operate, it is argued that the activities proposed allow the new language data from the text to be processed and stored more effectively, developing language, and L2 reading fluency, and language awareness.

\section{8-233 DiCamilla, Frederick J. (Indiana U.) and} Anton, Marta. Repetition in the collaborative discourse of $L 2$ learners: a Vygotskian perspective. The Canadian Modern Language Review / La Revue canadienne des langues vivantes (Toronto, Ont.), 53, 4 (1997), 609-33.

The study reported here investigates the role of repetition in the discourse of 10 adult students of Spanish as a second language (L2) working on a writing assignment in collaborative dyads. Data were taken from audiotapes of the dyads' collaborative sessions. The occurrences of repetition (of self or of the other member of the dyad) were analysed from the theoretical perspective based on the work of L. S.Vygotsky $(1978,1986)$, which argues that 'sociocultural and mental activity are bound together in a dependent, symbolically mediated, relationship' (Lantolf \& Pavlenko, 1995). This study seeks to show that the sociocultural and mental activity of the subjects is mediated by the repetition of both first and second language utterances, the effect of which is to create and maintain a shared perspective of the task (i.e. intersubjectivity) and to construct scaffolded help, which enables them to complete their tasks.

\section{8-234 Edmondson, Willis J. (U. of Hamburg).} Sprachbewußtheit und Motivation beim Fremdsprachenlernen. [Language awareness and motivation in learning foreign languages.] Fremdsprachen Lehren und Lernen (Tübingen, Germany), 26 (1997), 88-110.

The author investigates the interplay of (foreign) language awareness (as opposed to language knowledge) and motivation among trainee language teachers at the University of Hamburg. The data are taken from a database kept by the author which includes statements made by the students in respect of language awareness and motivation from their own experiences of foreign language learning. The data suggest that there is a link between motivation and language awareness, and the author develops a model for the development of language (learning) awareness documented by statements from the database concerning awareness. It is stressed that the concept of language awareness may in some way help to make better use of language learning opportunities, and so perhaps to obviate so-called 'lost opportunities'. 
98-235 Finkbeiner, Claudia (U. of Gießen). Zur affektiven und kognitiven Dimension beim Lesen: Bericht von einer Untersuchung zum

Zusammenwirken von Interessen und Lerstrategien. [On the emotional and cognitive dimension of reading: report of a study of the interplay of interests and learning strategies.] Zeitschrift für Fremdsprachenforschung (Bochum, Germany), 8, 2 (1997), 197-212.

The author describes a study of the interplay of interests and learning strategies as used in text comprehension in a foreign language. For the most part the article is concerned with the development and design of suitable procedures for testing such interplay, with particular focus on the theoretical rationale behind the design. The devised testing methods were used on 14 ninthgrade classes (second year post-primary) from grammar and comprehensive schools in the German province of Baden-Württemberg, giving a total test population of 350 learners of English as a Foreign Language; this is to form the first phase of a more extensive study run from the University of Gießen. Statistical analyses of this first phase of the study are presented and some of the more statistically relevant correlations between interests and learning strategies (categorised according to criteria set forth in O'Malley \& Chamot (1990)) are highlighted.

\section{8-236 Firth, Alan (Aalborg U., Denmark) and Wagner, Johannes. On discourse, communication, and (some) fundamental concepts in SLA research. The Modern Language Journal (Madison, WI), 81, 3 (1997), 285-300.}

This article argues for a reconceptualisation of Second Language Acquisition (SLA) research that would enlarge the ontological and empirical parameters of the field. It is claimed that methodologies, theories, and foci within SLA reflect an imbalance between cognitive and mentalistic orientations, and social and contextual orientations to language, the former orientation being unquestionably in the ascendancy. This has resulted in a skewed perspective on discourse and communication, which conceives of the foreign language speaker as a deficient communicator struggling to overcome an underdeveloped competence in the second language, striving to reach the 'target' competence of an idealised native speaker. The authors contend that SLA research requires a significantly enhanced awareness of the contextual and interactional dimensions of language use, an increased 'emic' (i.e., participant-relevant) sensitivity towards fundamental concepts, and the broadening of the traditional SLA data base. With such changes in place the field of SLA has the capacity to become a theoretically and methodologically richer, more robust enterprise, better able to explicate the processes of second or foreign language acquisition, and better situated to engage with and contribute to research commonly perceived to reside outside its boundaries.
98-237 Freland-Ricard, M. (U. Aix-Marseille I). Organisation temporelle et rythmique chez les apprenants étrangers. Etude multilingue. [Temporal and rhythmic aspects of foreign language learners' performance: a multilingual study.] Revue de Phonétique Appliquée (Paris), 118-119 (1996), 62-91.

This article, which analyses certain prosodic aspects of foreign language learners' speech, has two main aims. The first is to identify and describe certain 'errors' committed by foreign students, and the second is to show that unless such learners receive relevant training, their speech production in the foreign language will remain based on the prosodic system of their mother tongue. The article is based on data obtained through the instrumental phonetic and statistical analysis of recordings of groups of native speakers of French, German, Spanish, Danish, Norwegian and American English, which shows that learners adopt strategies for the management of temporal aspects of speech which are different from those of native speakers, and that they fail to identify patterns and units of intonation in the target language, or to distinguish between them. It is argued that such observations fully justify the inclusion of lessons specifically devoted to prosody from the very beginning of a programme of foreign language instruction.

\section{8-238 Gajo, L. (U. de Neuchâtel).}

Décontextualisation et récontextualisation dans l'apprentissage scolaire et non-scolaire d'une langue seconde. [Decontextualisation and recontextualisation in in-school and out-of-school second language learning.] Revue de Phonétique Appliquée (Paris), 121, (1996), 311-25.

This paper sets out to describe certain characteristics of the ways in which young immigrants learn French and German in French-speaking Switzerland.The conceptual and methodological framework draws on three concepts related to the analysis of metalinguistic aspects of discourse: double voicing (to be found in the discourse of a teacher who is both teaching and participating in a role-play), double focus (in exolinguistic discourse, for example, where speakers pay attention both to the content and the form of the message), and polyphony (different voices or sources present in the same utterance). Examples of conversation are analysed to show that different combinations of these factors are to be found in in-school and out-of-school discourse. Moreover, decontextualisation and recontextualisation procedures, which are known to be directly involved in the learning process, also vary between the two situations.

\section{8-239 Gardner, R. C., Tremblay, Paul F. and Masgoret, Anne-Marie (U. of Western Ontario).} Towards a full model of second language learning: an empirical investigation. The Modern Language Journal (Madison, WI), 81, 3 (1997), 344-62.

Much research in second language acquisition (SLA) centres on the relationships among individual difference 
measures such as language attitudes, motivation, anxiety, self-confidence, language aptitude, learning strategies, field independence, and measures of achievement in the language. Numerous studies have supported the proposed influences of these individual difference variables on achievement, and a number of models have been developed to explain the relationships among subsets of these variables. However, there is a lack of research examining the relationships among all these variables simultaneously. The study reported here investigated a large number of individual difference measures to determine their underlying dimensions, to contrast their predictive validities, and to evaluate their contributions in a causal model of SLA. The study was based on a sample of 102 university students enrolled in introductory French.The results indicated substantial links among the affective measures and achievement. Support was found for these connections in the proposed causal model.

98-240 Goh, Christine (Nanyang Tech. U., Singapore). Metacognitive awareness and second language listeners. ELT Journal (Oxford), 51, 4 (1997), 316-9.

This article reports on a diary study that revealed beliefs and knowledge second language learners had about their listening. An analysis of the diaries of 40 English as a Second Language learners from China (average age 19) revealed that many of them had clear ideas about three aspects of listening: their own role and performance as second language listeners, the demands and procedures of second language listening, and strategies for listening. The article discusses the implications of these findings for the teachng and learning of listening in English language teaching programmes. It calls for more discussion to increase learners' metacognitive awareness in listening, and argues for the use of listening diaries as a learning tool for this purpose.

98-241 Hancock, Victorine (U. of Stockholm). Parce que: un connecteur macro-syntaxique. L'emploi de parce que chez les apprenants de français langue étrangère et des locuteurs natifs. [Parce que ('because'): a macro-syntactic connective. The use of parce que by learners of French as a foreign language and by native speakers.] Aile (Paris), 9 (1997), 117-45.

This paper compares the function of the French connective parce que ('because') in the spontaneous oral production of Swedish-speaking learners of French and of French native speakers. The authors apply a syntactic and pragmatic approach which is based on recent research in spoken French, and which is motivated by the need to describe syntactic relations that are not restricted to the sentence but concern sequences of speech. They attempt to seek explanations for the observed overuse of parce que by the non-native speakers, at a level which concerns both the semantic and the discourse functions of the connective. They also consider the role of parce que in the hierarchical organisation of spontaneous discourse, and suggest that this feature of the use of parce que might indicate an advanced level of acquisition in learners.

98-242 Hawkins, Roger (U. of Essex) and Yuethung Chan, Cecilia. The partial availability of Universal Grammar in second language acquisition: the 'failed functional features hypothesis'. Second Language Research (London), 13, 3 (1997), 187-226.

A number of studies in the research literature have proposed that Universal Grammar (UG) is partially available to adult second language learners. Attempts to provide a syntactic characterisation of that partial availability have only recently begun to appear, however. This article argues that speakers of Chinese (a language without $w h$-operator movement in overt syntax) learning second language English (a language with wh-operator movement in overt syntax) establish mental representations for English which involve pronominal binding rather than operator movement. It is suggested that this divergence from native-speaker representations is an effect of the inaccessibility of features of functional categories in second language acquisition, what the authors refer to as the 'failed functional features hypothesis'. Implications are drawn from the findings for the syntactic characterisation of accessibility to UG more generally in second language acquisition.

\section{8-243 Holtzer, Gisèle (U. of Franche-Comté,} Besançon). Conduites et stratégies dans l'apprentissage à distance d'une langue étrangère. [Behaviours and strategies in foreign language learning in distance mode.I Le Français dans le Monde (Paris), special issue (July 1997), 105-15.

This paper gives details of strategies used by adult French learners following a 'pluri-media' distance course in Chinese (paper, audio- and video-tape). The details are drawn from the analysis of student reports based on learning journals. Three types of behaviour are noted: use of problem-solving strategies as the result of moments of realisation; routine learning behaviours, built on earlier learning experiences ('blind strategies'); and information-storing techniques. The journals suggest that it is only when learners face seemingly insurmountable difficulties that different strategies are seriously contemplated. The paper also gives an account of the ways in which learners use the three types of learning support and of the functional practices used by the most motivated. Finally, the paper argues for the need for interactive discussion of strategies used in specific situations between learners and between learners and teachers. It is suggested that teachers have much to gain from listening to learners. 
98-244 Kamma, Karolien (Hoofdweg 307-1, 1057 CZ Amsterdam). Kijkend leren: een onderzoek naar het lerenn van woorden in een vreemde taal via de televisie. IWatching to learn: research on the learning of words in a foreign language through television.] Toegepaste Taalwetenschap in Artikelen (Amsterdam), 56, 1 (1997), 9-21.

The research reported on in this paper concerns the role of television in the lexical acquisition of a foreign language. 20 higher-educated adult learners of Dutch as a foreign language watched a 15-minute compilation of the educational programmes Klokhuis and Lucht. A preand post-test design was used to examine whether the participants learned words by watching and listening to the programmes. The results indicated a significant learning effect, which persisted after a one-week interval. There was also a tendency for the learning effect in the 10 students who watched with explicit word-learning instruction (intentional learning) to be stronger than in those who watched without instruction (incidental learning). The learnability of a word was apparently neither positively influenced by the visual support television provided as an extra contextual cue, nor by the number of times a word was offered in the television fragments. It is concluded that television can play an important role in the lexical acquisition of Dutch as a foreign language.

98-245 Kanno, Kazue (U. of Hawai'i, Mānoa). The acquisition of null and overt pronominals in Japanese by English speakers. Second Language Research (London), 13, 3 (1997), 265-87.

This article reports on an experimental study that examines the role of Universal Grammar (UG) in the second language (L2) acquisition of Japanese by English speakers. The study focuses on the acquisition of the principle that prevents overt pronouns from having quantified Noun Phrases (NPs) as antecedents in languages (such as Japanese) that have null pronouns. A group of 28 English speakers taking a fourth semester course in Japanese were asked to interpret the null and overt pronominal in the Japanese equivalent of patterns such as Everyone ${ }_{i}$ thinks he $/ \mathrm{O}_{i}$ is smart. Not only did the L2 learners exhibit a statistically significant difference in their interpretation of null and overt pronominals with respect to binding by a quantified NP, consistent with the UG principle, but their performance was not significantly different from that of a native-speaker control group.

\section{8-246 Kita, Kenji and Ogata, Hiroaki}

(Tokushima U., Japan). Collocations in language learning: corpus-based automatic compilation of collocations and bilingual collocation concordance. Computer Assisted Language Learning (Lisse, The Netherlands), 10, 3 (1997), 229-38.

While corpus-based studies are becoming a new methodology in natural language processing, second language learning seems to be an interesting potential application too. This paper is primarily concerned with the acquisition of collocational knowledge from corpora in order to use it in the language learning process. The authors present what is deemed an efficient method for extracting collocations from corpora, which uses the cost criteria measure and a tree-based data structure. They also propose a bilingual collocation concordancer, a tool that provides language learners with collocation correspondences between a native language and a foreign language. Language learners can refer to these concordance outputs during their language learning activities.

98-247 Knapp-Potthoff, Annelie (Universität GH Siegen). Sprach(lern)bewußtheit im Kontext.

[Language Awareness in context.] Fremdsprachen Lehren und Lernen (Tübingen, Germany), 26 (1997), 9-23.

Starting from reflections upon the current attractiveness of the concept of Language Awareness, this article presents a critical discussion of the vagueness of the concept itself and its potential benefits for second language learning. In particular, it is argued that Language Awareness-as it is generally conceived of-is not easily accessible to empirical research, and that the problem of different qualities of learners' Language Awareness is largely neglected. It is suggested that a conceptualisation of Language Awareness as the ability and readiness to develop adequate and (potentially) explicit subjective theories of language(s) and language learning presents a more promising framework for empirical research. Several hypotheses concerning influences upon learners' subjective theories and their relation to foreign language learning are proposed.

98-248 Leow, Ronald P. (Georgetown U.). Attention, awareness, and foreign language behaviour. Language Learning (Cambridge, MA), 47, 3 (1997), 467-505.

The study reported here qualitatively and quantitatively addressed the role of awareness in relation to Schmidt's noticing hypothesis in second language acquisition $(1990,1993,1994,1995)$. It analysed both the thinkaloud protocols produced by 28 beginning adult second language learners of Spanish (selected carefully from a pool of 85 people on the basis of relevant criteria) completing a problem-solving task, and their immediate performances on two post-exposure assessment tasks, a recognition and written production task. The qualitative and quantitative analyses of learners' performances suggest the following conclusions: (a) different levels of awareness lead to differences in processing; (b) more awareness contributes to more recognition and accurate written production of noticed forms; and (c) the findings provide empirical support for the facilitative effects of awareness on foreign language behaviour. 
98-249 Little, David (Trinity Coll., Dublin). Language awareness and the autonomous language learner. Language Awareness (Clevedon), 6. 2/3 (1997), 93-104.

This paper offers a language-awareness perspective on the concept of autonomy in second language learning. The introductory section distinguishes between two kinds of language awareness and elaborates a working definition of learner autonomy. The second section looks at child development and the role played by both kinds of language awareness in first language acquisition. It considers in turn the importance of context in developmental learning, the role played by the growth of metalinguistic knowledge in first-language acquisition, and the impact of literacy on first language development. The third section is concerned with the role played by both kinds of language awareness in second language pedagogy. It begins by reflecting on the shortcomings of the grammar-translation approach, then suggests reasons for the relative failure of the so-called communicative approach, and ends by proposing a reassessment of the role of writing in second language learning.

98-250 Lynch, Tony (IALS, Edinburgh U.). Life in the slow lane: observations of a limited $L 2$ listener. System (Oxford), 25, 3 (1997), 385-98.

This paper discusses an intermediate-level learner's progress in listening comprehension during a pre-sessional English for Academic Purposes (EAP) course in the U.K. It presents evidence from three sources: product (the learner's answers to entry and exit listening tests); process (his negotiation of meaning in the classroom) and his perceptions (of listening difficulties after the course). It highlights the difference in progress in oneway and two-way listening, and the discrepancy between performance within the sheltered setting of the language classroom and success in real interaction in the academic world outside.

98-251 Masny, Diana (U. of Ottawa). Linguistic awareness and writing: exploring the relationship with language awareness. Language Awareness (Clevedon), 6, 2/3 (1997), 105-18.

This paper explores the inter-relationships between linguistic awareness and language awareness with regard to second-language teaching and learning. In the secondlanguage classroom, language awareness, as an interface mechanism, promotes heightened awareness of language forms between the first language (L1) and the target language (TL) and thereby assists language learning. Linguistic awareness refers to the learners' reflection on and manipulation of the language code. This paper proposes that findings from research studies on linguistic awareness can inform practices in language awareness. One such study is provided here as an example. This particular study examines the relationship between linguistic awareness and writing in two groups of college students. In one group, data were collected in
French (L1) and in English (L2). In the second group, data were collected in English (L1). Linguistic awareness was measured by means of two tasks: acceptability judgements and mazed-reading. The writing task, an essay, was designed to measure decontextualised writing (explicit contextualisation). While this study is situated in psycholinguistic theory, the findings call for explanations grounded cognitively, socially and culturally. These explanations can provide richer and thicker descriptions of the contributions of the study to a deeper understanding of language awareness.

98-252 Meisel, Jürgen M. (U. of Hamburg and Netherlands Inst. for Advanced Study). The acquisition of the syntax of negation in French and German: contrasting first and second language development. Second Language Research

(London), 13, 3 (1997), 227-63.

The acquisition of negation is perhaps the best-studied syntactic phenomenon in early interlanguage research, and many of these publications concluded that first (L1) and second language (L2) development had much more in common than had previously been assumed. This paper re-examines the problem of whether the same underlying principles and mechanisms guide $\mathrm{L} 1$ and $\mathrm{L} 2$ acquisition, from the perspective of more recent grammatical theory. The empirical basis consists of longitudinal case-studies of the acquisition of French and German as first and second languages. The L2 learners' first language is Spanish. In L1 data one finds a rapid, uniform and almost error-free course of development across languages exhibiting quite different morphosyntactic means of expressing negation. This is explained in terms of Parameter Theory, primarily referring to functional categories determining the placement of finite verbal elements. L2 acquisition, on the other hand, is characterised by considerable variability, not only crosslinguistically, but also across learners and even within individuals. This can be accounted for by assuming different strategies of language use. More importantly, different kinds of linguistic knowledge are drawn upon in $\mathrm{L} 1$ as opposed to L2. It is claimed that adult L2 learners, rather than using structure-dependent operations constrained by Universal Grammar, rely primarily on linear sequencing strategies which apply to surface strings.

\section{8-253 Mondria, Jan-Arjen (U. of Groningen,} the Netherlands). Woorden leren: context, raden en onthouden. [Vocabulary learning: context, guessing and memorising.] Levende Talen (Amsterdam), 523 (1997), 476-80.

Learning psychologists would argue that contextualised learning is superior to decontextualised learning, and that learners guessing word meanings leads to better retention than teachers simply giving them. However, these claims have not been unequivocally supported by empirical findings. The present study hoped to provide such support in the context of learning foreign language vocabulary. In a number of experiments, Mondria compared the effectiveness of different memorisation strategies in 
Dutch secondary school learners of French (age 13-14; second year of French). The results support the first claim: the retention of words learned in context is superior to list learning, with full texts used as contexts leading to even better results than just sentences. The claim that learners guessing would be superior to teachers giving word meanings was not substantiated: the methods appeared to be equally effective. The author stresses that the results do not suggest that imprinting isolated word meanings is useless: in actual practice, learners will most likely encounter new words in context; when they subsequently sit down and imprint them, the context will resonate, as it were. He also stresses that, although 'guessing' may not be the most efficient learning strategy, it certainly is very valuable as a compensatory strategy. As a learning strategy, retention is better when 'guessing' is followed by 'verification'.

98-254 Multhaup, Uwe (Bergische Universität, Germany). Mental networks, procedural knowledge and foreign language teaching. Language Awareness (Clevedon), 6, 2/3 (1997), 75-92.

This paper first outlines what is to be understood by procedural knowledge, at a time when a growing number of researchers call for more process-oriented language courses to replace the old factual-oriented courses. The author discusses why this term, which comes from the fields of cognitive psychology and information processing research, has gained such prominence in secondlanguage acquisition and foreign language teaching research, and how it relates to implicit and explicit knowledge and to language awareness. A neurobiologically based model of the mental processes involved in the acquisition and use of language knowledge is presented. It aims to provide a theoretical framework for understanding the bewildering variety of definitions of procedural knowledge found in the literature. The author distinguishes between a procedural knowledge which is implicit in the structures of declarative knowledge and a procedural knowledge which is needed for their generation. This entails a dialectical understanding and awareness of language as process and product which presuppose and modify each other in a hermeneutical circle of knowledge and experience. In this context the author discusses how pedagogical tasks and instruction can enhance procedural knowledge and language awareness.

\section{8-255 Nakuma, Constancio (Tennessee U.).} Loss of communicative competence: measurability and description of a method. IRAL (Heidelberg. Germany), 35, 3, (1997), 199-209.

The first part of this paper discusses the measurability of communicative and linguistic competence. It is shown that contemporary linguistic thinking, by suggesting that linguistic competence is measurable only to the extent that it is revealed by linguistic performance, effectively reduces the domain of language attrition research to the performance dimension only. It is argued that both the performance and the competence dimensions need to be treated as mutually presupposing each other, as opposed to the prevailing viewpoint whereby only performance is considered as presupposing competence, but not the other way round. The second part describes a method of measuring attrition of communicative competence using spontaneous speech data. The method uses a multi-factor index of defined temporal variables, frequency counts of selected verbal behaviours, and grammatical information to measure either rate of attrition or its reverse. The method purports to demonstrate in one quantity the extent and direction of evolution of a subject's communicative (or linguistic) competence, relative to a determined baseline competence level.

\section{8-256 Palmen, Marie-José, Bongaerts, Theo and Schils, Erik (U. of Nijmegen). L'authenticité de la prononciation dans l'acquisition d'une langue étrangère au-delà de la période critique: des apprenants néerlandais parvenus à un niveau très avancé en français. IAn authentic accent in foreign language learning beyond the critical period: Dutch learners of French at a very advanced level.] Aile (Paris), 9 (1997), 173-91.}

This paper reports on the third of three studies investigating Scovel's (1988) claim that an authentic accent in a foreign language is unattainable for those who start to acquire the language after the close of the biologicallybased 'critical period' for language learning. Speech samples from two groups of Dutch learners of Frenchone of them very advanced-and a native-speaker control group were judged for accent by French native speakers. Analysis of the judgements revealed that three learners could indeed pass for native speakers of French. It is claimed that these results suggest that there is no absolute biological barrier to the acquisition of an authentic accent in a foreign language. It is also suggested that the success of the exceptional learners in this study may have been at least partly due to a combination of certain learner and learning context factors.

98-257 Py, Bernard (Neuchâtel U.). Quelques remarques sur l'apprentissage du lexique d'une langue étrangère. lObservations on learning the lexis of a foreign language.] Cahiers de Lexicologie (Paris), 70, 1 (1997), 175-84.

This paper begins by suggesting that the notion of microsystem leads to a better understanding of some aspects of learning a foreign language and, in particular, the lexis, which occupies a pivotal position in exo-lingual communication (particularly in situations of 'verbal distress') and learning the linguistic skills that are required to master it. It would appear that learners organise the major part of their communication and learning effort around the lexis, and, for example, much less around the syntax. Words enable the learner to enter the new language and to build up an interlanguage. The paper discusses the study of these learning 
processes, using observations of oral dialogue data consisting of verbal interactions between learners and native speakers.

\section{8-258 Regan, Vera (U. Coll. Dublin). Les} apprenants avancés, la lexicalisation et l'acquisition de la compétence sociolinguistique: une approche variationniste. [Advanced learners, lexicalisation and the acquisition of sociolinguistic competence: a variationist approach.] Aile (Paris), 9 (1997), 193-210.

This article describes the variationist approach to second language acquisition research. It offers an example of the way in which variationist quantitative analysis can facilitate the understanding of certain aspects of the acquisition process. In relation to lexicalised phrases, the literature suggests that early learners use such phrases in a process of analysis of the grammar of the target language. The study reported here focused on the use of lexicalised phrases by advanced learners of French as a second language in Ireland. The analysis suggested that these phrases are also important for advanced learners, but may be used by them as a sociolinguistic strategy.

\section{8-259 Skehan, Peter and Foster, Pauline}

(Thames Valley U.). Task type and task processing conditions as influences on foreign language performance. Language Teaching Research (London), 1. 3 (1997), 185-211.

This paper examines the effects of planning and posttask activity on task-based performance. It is motivated by the need, given recent claims that task-based instruction has desirable pedagogic qualities, to investigate the effects of choosing different types of tasks, as well as different task implementation conditions, on the fluency, accuracy and complexity of the language which is produced when tasks are carried out. Three tasks are investigated: a personal task, a narrative task and a decision task. A 2-by-2 research design was used, with two planning conditions (10 minutes' planning time vs no planning time) and two post-task conditions (plus or minus knowledge of a post-task). Performance was assessed through the number of pauses (as a measure of fluency), the percentage of error-free clauses (to measure accuracy) and the level of subordination (as a measure of complexity). Confirming hypotheses and previous research, planning had clear effects on almost all measures. The hypothesis that foreknowledge of a post-task activity would selectively influence accuracy received only partial confirmation. Data from the present study were also related to results in an earlier study. This revealed that there is strong evidence of trade-off effects between the different dependent variables used, in that fluency, accuracy and complexity seem to enter into competition with one another, given the limited attentional capacities of second language users. Finally, there are indications that task characteristics interact with planning time and lead to selective improvements in particular areas. Tasks which contain clearer inherent structure, when planned, seem to favour accuracy, whereas tasks which require more on-line processing or which have complex outcomes, when planned, produce greater complexity.

\section{8-260 Suenobu, Mineo, Yamane, Shigeru and Kanzaki, Kazuo (Kobe U. of Commerce, Japan). Information transmission of English by Japanese learners of English. IRAL (Heidelberg, Germany), 35, 3 (1997), 187-97.}

The study reported here investigated the process whereby Japanese learners of English transmit information in the target language. 70 Japanese university students were shown four pictures constituting a story-sequence, which they were asked to describe in two minutes. The same procedure was repeated four times, and the process of information transmission was observed. The relationship between the number of utterances and amount of information was also analysed. The data analysis indicated that: (a) the number of utterances produced by the learners was not necessarily related to the amount of information; (b) sentence patterns and the distribution pattern of parts of speech in the learners' English differed from native speakers' English; and (c) the learners' spoken ability could not necessarily be judged from the results, i.e. if they were allotted sufficient time, they had the potential ability to produce a major part of the story unaided. Pedagogical implications are discussed.

98-261 Tajino, Akira (Hiroshima Shudo U.). Learner difficulty: what is it, and how well do we understand it? The Teacher Trainer (Canterbury), 11, 2 (1997), 12-14.

Teachers, whatever they teach, have to recognise and understand what is difficult for their learners. This article sets out to explain three main perspectives on the notion of difficulty, and to put forward the author's view that difficulty is a psychological rather than a purely observable or linguistic issue. Secondly, he explains why learner perception is important for motivational reasons, and thirdly suggests that teachers are not always good at diagnosing learner difficulty. Citing research on infant school teachers that shows they had difficulty diagnosing learner problems and even seemed at times to believe it was unnecessary to do so, the author claims, as a result of his own research on high school English as a Foreign Language (EFL) students in Japan, that EFL teachers are no better at identifying learner perception. The article concludes with a plea for teachers to recognise that learner perception is unobservable, important in motivation, and involves the development of the trainable quality of empathic understanding in teachers. 
98-262 van Hell, Janet G. and Candia Mahn,

Andrea (U. of Amsterdam). Keyword mnemonics versus rote rehearsal: learning concrete and abstract foreign words by experienced and inexperienced learners. Language Learning (Cambridge, MA), 47, 3 (1997), 507-46.

The two studies reported here examined the efficacy of the keyword method $v s$. rote rehearsal in learning foreign language (FL) vocabulary. In Experiment 1, 36 experienced Dutch learners of FLs, naive with regard to the target language (Spanish), participated. In Experiment 2, the 40 participating Americans, all inexperienced FL learners, were exposed to Dutch words. In both experiments, the concreteness of the novel foreign words and the quality of the keyword as a retrieval cue were manipulated: half the concrete and abstract words were linked to a meaningfully related keyword, the rest to a semantically unrelated keyword. Learning was assessed immediately after the learning phase, and again after a one-week and two-week delay. Performance was expressed in proportion correct and reaction times of the orally produced translation responses. In experienced FL learners, rote learners' performance bettered that of keyword learners. In inexperienced learners, rote learners and keyword learners recalled the same proportion of words, though keyword learners had longer retrieval times. It is concluded that keyword imagery does not impede the learning of abstract word meanings; and keywords meaningfully related to the foreign word form more effective retrieval cues than semantically unrelated words.

98-263 Wayland, Ratree (Cornell U.). Non-native production of Thai: acoustic measurements and accentedness ratings. Applied Linguistics (Oxford), 18, 3 (1997), 345-73.

This paper reports a study of the production of Thai vowels, consonants and tones by native speakers (NSs) of English. Three Thai NSs and six English NSs were audio-recorded in an oral reading task. The investigation focused on: (a) measurement of the acoustic parameters along which the two groups of speakers differ, and (b) which of these parameters influenced native Thai-speaking listeners' judgments of perceived degree of accentedness. Speech analysis showed that they differed more along the spectral dimension (i.e. formant frequencies and fundamental frequency) than the temporal dimension (i.e. voice-onset time and vowel duration). Rated for accentedness, the rating data showed that non-native (NN) and native production can be readily distinguished; only some $\mathrm{NN}$ tokens were judged 'native-like'. Moreover, the rating scores for the NNSs were lower in level tones than contour tones, suggesting different degrees of difficulty for each. When the acoustic data were regressed on the rating data, significant predictors were spectral in nature and found mostly for level tones; and no correlation was found between years of experience with Thai and the rating scores. Results are discussed in terms of an 'holistic' vs. 'analytic' approach in tone processing by adults, inherent acoustic characteristics of individual tones as well as quantity and quality of the native input. That some NN tokens were judged 'native-like' seems to challenge the claim that segmental as well as suprasegmental errors arise from the loss of ability to learn NN sounds.

98-264 Weltens, Bert (Katholieke U., Nijmegen). Vijftien jaar Nijmeegs taalverliesonderzoek. IFifteen years of language attrition research in Nijmegen: State of the art.l Toegepaste Taalwetenschap in Artikelen (Amsterdam), 56, 1 (1997), 63-74.

Research in Nijmegen into language attrition started in 1982, inspired by a 1980 American conference, the proceedings of which were published in The loss of language skills (edited by Lambert \& Freed; Rowley, MA: Newbury House, 1982). Language attrition research aroused a great deal of interest in the Netherlands as well as elsewhere. The question of what happens to foreign-language skills learned at school was-and still is-considered particularly relevant. Many Dutch people know from personal experience that several years' of learning French at school can still leave them lost for words when, years later, they come to book a hotel room. The original research question was how much is lost and what is lost? 15 years and a number of projects later, researchers in the Netherlands have come to realise that things are not as bad as supposed, in the Netherlands at least, for the subjects and skills tested. The skills tested were frequently found to remain intact across very long periods of time, and in some cases even improved, even with virtually no exposure to the target language. This paper presents an overview of the findings obtained in the 15 years of $\mathrm{Nijmegen}$ research into language attrition, leading to possible avenues for research in the next 15 years.

98-265 Wilhelm, Kim Hughes (Southern Illinois U.). Use of an expert system to predict language learning success. System (Oxford), 25, 3 (1997), 317-34.

The major purpose of the study reported here was to examine a number of language learning background variables in relationship to rate of progress through an intensive English programme (IEP). In the first stage of the study, a knowledge bank of 40 background variables for 201 subjects was refined to those variables which most clearly showed 'maximum interclass difference' when comparing three categories of success. In the second stage of the study, the extent to which success category could be accurately predicted by an expert system was measured, basing prediction on (a) all 40 variables, (b) learner-reported language learning background variables, and (c) IEP entry proficiency measurements. Results indicated that entry proficiency variables were most effective when predicting high and low success category, but language learning background variables were most effective when predicting medium success. A brief introduction to knowledge base expert systems is provided as part of the background to the study. 